\title{
Role of community nurses in the prevention of tuberculosis in the Tshwane Health District of Gauteng
}

\author{
Authors: \\ Siphiwe D. Mnisi ${ }^{1}$ \\ Mmapheko D. Peu ${ }^{2}$ \\ Salomé M. Meyer ${ }^{3}$ \\ Affiliations: \\ ${ }^{1}$ Department of Health, \\ SG Lourens Nursing College, \\ South Africa \\ ${ }^{2}$ Department of Nursing \\ Science, University of \\ Pretoria, South Africa \\ ${ }^{3}$ Clinical Arts and Technology \\ Centre, New Zealand \\ Correspondence to: \\ Mapheko Peu \\ Email: \\ doriccah.peu@up.ac.za \\ Postal address: \\ PO Box 667, Pretoria 0001, \\ South Africa \\ Dates: \\ Received: 22 Aug. 2011 \\ Accepted: 07 Aug. 2012 \\ Published: 09 Nov. 2012 \\ How to cite this article: \\ Mnisi, S.D., Peu, M.D. \& \\ Meyer, S.M., 2012, 'Role of \\ community nurses in the \\ prevention of tuberculosis in \\ the Tshwane Health District \\ of Gauteng', Curationis \\ 35(1), Art. \#47, 9 pages. \\ http://dx.doi.org/10.4102/ \\ curationis.v35i1.47
}

(C) 2012. The Authors. Licensee: AOSIS OpenJournals. This work is licensed under the Creative Commons Attribution License.
The objectives of this study were to identify the role of community nurses in the prevention of tuberculosis (TB) and to identify problems experienced by them when fulfilling this role in the Tshwane Health District of Gauteng. A non-experimental, descriptive, quantitative research design method was used to collect data from community nurses. The sample included 59 registered nurses who voluntarily agreed to participate in the study. A questionnaire was used to collect data and quantitative data analysis methods were employed. Various opinions and ideas on the role of community nurses in the prevention of TB and the problems experienced were identified. Based on the results of this research, measures to protect community nurses from contracting TB whilst on duty should be a priority. Government should support TB programmes by providing money to non-governmental organisations and direct observed treatment short course (DOTS) supporters to make follow-up visits to patients possible, thus reducing the number of defaulters. Stringent measures should be taken at all border points to ensure that foreigners are screened for $\mathrm{TB}$, multidrug-resistant $\mathrm{TB}$ and extensively drugresistant TB. This study was limited to community nurses in the Tshwane Health District of Gauteng who were registered with the South African Nursing Council (SANC) and therefore this study could not be generalised to registered nurses in the hospital setting or even to clinics in the rest of South Africa.

\section{Introduction}

\section{Background}

For many years tuberculosis (TB) has been one of the killer diseases in South Africa. It is still a major health problem, despite the fact that it is both preventable and curable. The World Health Organization (WHO), cited in Smeltzer et al. (2010:567), estimated that about 1\% of South Africans (roughly 490 000) contracted TB in 2008. According to Vlok (2006:515), TB is associated with poverty and poor living conditions, which make a person particularly susceptible to TB if he or she comes into contact with an infected person.

The WHO found that TB is the second highest cause of death globally (WHO 2005:1), after the human immunodeficiency virus (HIV) and acquired immunodeficiency syndrome (AIDS), as it kills nearly two million people every year. A few years ago it was thought that TB could be successfully treated and even perhaps prevented by advances in medical treatment such as chemotherapy. Unfortunately this has not been the case, and TB can still be fatal (Toth et al. 2004:28). Africa is one of the countries with the highest incidence of TB. It is estimated that 2.4 million new TB cases are diagnosed and 540000 deaths are caused by TB every year (WHO 2005:1).

Controlling TB effectively is not the responsibility of healthcare workers alone; it is also the responsibility of each individual to prevent the spread of TB. This view is supported by the results of a study conducted by Richter and Peu (2004:38) who found that caregivers can help increase awareness of the community of their right to access effective TB care. Caregivers should make people aware of DOTS therapy, and assess environmental conditions to determine whether the community's needs are being met (Richter \& Peu 2004:38).

Molefe (1999:178), supported by Dick et al. (2007:383), stated that the current approach to TB control is based at the primary healthcare level, but this poses a problem for community nurses as it increases their workload and responsibilities. This leads to the question of what the role of community nurses is in the prevention of $\mathrm{TB}$, especially in the face of its rapid escalation. If the incidence of TB increases further, this will have an influence on the role played by nurses in the community. Nurses have to realise that they are the pillars of TB prevention and management. Community nurses have the opportunity to assess, diagnose, treat and refer patients with TB for further care. 
Despite the fact that DOTS had 93\% coverage in 2004, South Africa continues to notify the WHO of more TB cases (WHO 2005:1). A variety of activities can be put in place to prevent the increase of $\mathrm{TB}$, and the role of community nurses in these activities should be considered. It has been speculated that TB will have a serious impact on South Africa's economy because of the death rate amongst people in their productive years: $61 \%$ of people between the ages of 20 and 39 years and $26 \%$ of people between the ages of 40 and 49 may die because of TB (Van Rensburg 2004:255). Van Rensburg (2004:255) suggested that South Africa should adopt strategies similar to those used by Vietnam and Peru, which have demonstrated the effect of well-functioning control programmes on both morbidity and mortality.

Van Rensburg (2004:255) points to the Western Cape as the province with the worst TB statistics, with an infection rate of 559 per 100000 people annually, almost double the rate of all new infections in the country. It is almost seven times higher than that of Limpopo (85.9 per 100 000), the province with the lowest reported incidence of TB. KwaZulu-Natal showed a TB incidence rate of $64.6 \%$, followed by Mpumalanga with 59.1\% and the Free State with 51.7\% (Van Rensburg 2004:255).

\section{Problem statement}

Statistics indicate that there is an alarming shortage of registered nurses in South Africa. This was supported by the South African Nursing Council's geographical distribution in 2007, where it was noted that Gauteng had 9688100 of its population versus nursing manpower of 27201 registered nurses, and 10392 for South Africa. This is indicative that there are insufficient nurses to assist the country to prevent communicable diseases including TB.

In South Africa TB continues to result in the death of many patients, with more and more people in their productive years (between 20 and 49 years old) being critically affected by it, especially those in settings such as prisons and mines (Van Rensburg 2004:255; Smeltzer et al. 2010:567). Valid questions the researcher asked herself are: Are community nurses doing enough in the community to help prevent the increase of TB? Do they have the necessary knowledge and skills to contribute significantly and positively toward fighting this killer disease?

\section{Aim of the study}

The aim of the study was to investigate the role of community nurses in the prevention of TB in the Tshwane Health District of Gauteng.

\section{Objectives}

The following objectives guided the researcher throughout the study:

- To identify the role of community nurses in the prevention of TB in the Tshwane Health District in order to improve the part they play in the comprehensive management of TB patients.
- To identify the problems experienced by community nurses when fulfilling their role in the prevention of TB in the Tshwane Health District.

\section{Research questions}

The following questions were addressed in the course of the study:

- What role do community nurses play in the prevention of TB in the Tshwane Health District?

- What are problems experienced by community nurses in fulfilling their role when working with TB patients?

\section{Definition of key concepts}

Community nurses: Dreyer, Hattingh and Lock (1999:26) define a community nurse as 'a nurse, practicing in the community health field away from the formal structure of therapeutic institutions'.

Pulmonary tuberculosis: Pulmonary TB is defined by Smeltzer et al. (2010:567) as 'an infectious disease that primarily affects the lung parenchyma. Its causative organism is the Mycobacterium tuberculosis, of which there are a number of strains. This organism is transferred to a host by infected droplets from respiratory tract, sputum, dust and sometimes infected milk'.

Prevention: Tulchinsky and Varavinkova (2009:653) defined prevention as policies and actions that are aimed at eradication, minimising and eliminating the impact of the disease and disability or retarding its progress.

\section{Significance of the study}

The findings of this study identified problems experienced by community nurses in fulfilling their role in the prevention of TB, and could serve as a point of departure to making suggestions with regard to how these problems could be addressed.

\section{Research method and design}

A quantitative research method was applied in this study. A non-experimental descriptive survey was conducted by means of questionnaires to collect data from community nurses regarding their role in the prevention of $\mathrm{TB}$ and problems they experienced when fulfilling this role in the Tshwane Health District of Gauteng.

\section{Population and sampling}

The population for this study consisted of all community nurses registered with the SANC who work with TB patients in the Tshwane Health District of Gauteng. Fifty nine community nurses were conveniently selected from clinics which were systematically selected as lists were available (Burns \& Grove 2009:352). The researcher compiled a list of every clinic in the Tshwane Health District, and selected every third clinic from the list. Ten clinics were selected systematically from the total list of 35 clinics. Questionnaires 
were distributed to the selected clinics according to the number of community nurses who were available and on duty. The researcher analysed the roster of community nurses who were working with TB patients at the selected clinics with the help of facility managers (Burns \& Grove 2009:353).

A systematic probability sampling technique was employed. Probability sampling implies that every person in the targeted population has a chance of being selected (Parahoo 2006:259). Clinics in the Tshwane Health District of Gauteng that rendered comprehensive health care were systematically selected from the lists of clinics received from the Department of Health. The Tshwane Health District is divided into the following subdistricts: Southern, Central, Northern, Moretele and Odi. The following clinics were selected for the study but not all were used: Laudium, Stanza Bopape, Soshanguve, Bophelong, Boikhutsong, Ekangala, Themba, Boekenhout, Tlamelong, and others in the City of Tshwane Metropolitan Municipality (CTMM).

The researcher encountered a problem in one of the clinics, because the facility manager had a problem with the permission letter from the Department of Health. Ekangala clinic was under construction and was therefore not utilised. Therefore other clinics in the CTMM, namely Folang, Mamelodi West and Saulsville, were selected in its place in order to reach the predicted number of respondents.

The criteria for inclusion of community nurses in this study were that they be community nurses registered with the SANC with a year or more of experience in nursing (Burns \& Grove 2007:325). Fifty-nine community nurses completed and returned the questionnaires.

\section{Data collection}

In this study structured questionnaires were used to collect data. According to Polit and Beck (2012:297) a questionnaire 'is a document used to gather self-report data via selfadministration of questions'. A structured questionnaire was a suitable tool for data collection for this study because respondents were able to read and write.

The instrument was used to collect data from the sample, consisting of community nurses working with TB patients, regarding their role in the prevention of TB in the Tshwane Health District of Gauteng. Questionnaires were personally distributed to the selected clinics by the researcher. The respondents were expected to complete the questionnaire within 45 minutes. A period of two to three weeks was provided before questionnaires were collected by the researcher from the facility managers who kept them under lock and key. Sixty three questionnaires were distributed, 59 were answered and returned and four were unanswered and returned. Data were collected from February 2008 to April 2008.

\section{Data analysis}

Descriptive statistics, frequency counts and percentages for the Likert scale responses were used. Summary statistics on measured variables such as age, gender and experiences were employed by a statistician from the University of Pretoria who assisted with the data analysis. The findings of the study were presented by means of graphs, percentages and tables.

\section{Ethical considerations}

Written permission to undertake the study was obtained from the University of Pretoria Ethics Committee, the Gauteng Department of Health, both at provincial and regional level, and the CTMM, including the facility managers. A full explanation of the purpose of the study was given to community nurses in order to obtain verbal and written consent. Community nurses' rights to confidentiality and anonymity were guaranteed as they were expected not to write their names on the questionnaire.

\section{Validity and reliability}

According to Polit and Beck (2012:737) a pilot study refers to 'a small scale version or trial run done in preparation for a major study; sometimes called a feasibility study'. A pilot study was conducted using a sample of $10 \%$ of community nurses from a clinic rendering TB services in the Tshwane Health District of Gauteng. The respondents in the pilot study were not used for the study. Similar results or answers were obtained from the study's respondents and pilot study respondents, thereby demonstrating the consistency of the instrument.

Content validity concerns 'the degree to which an instrument has an appropriate sample of items for the construct being measured' (Polit \& Beck 2012:336). Content validity for this study was ensured through examination of the instrument by the researcher's supervisors as well as a professional statistician from the University of Pretoria. The researcher also requested the assistance of experts in the field of research in development of the questionnaire as well as the data analysis. Face validity refers to 'whether the instrument looks as though it is measuring the appropriate construct' (Polit \& Beck 2012:336). Face validity was ensured with the help of the researcher's supervisors and the statistician from the University of Pretoria.

\section{Discussion of results}

The results are presented under the following sections: demographic data, the role of community nurses, and problems experienced by community nurses when fulfilling their roles in the prevention of TB.

\section{Demographic data on age, qualifications and years of experience}

The question about age was answered by only 26 (44.07\%) of the 59 respondents; 33 (55.93\%) did not give their age. Most of the respondents, namely $9(34.62 \%)$, were in the $40-49$ years age range, followed by $6(23.08 \%)$ who fell into the 30-39years and 50-59 years age ranges. 
The question about professional qualifications was answered by only 53 of the 59 respondents (Figure 1). The percentages reflected in the figure are therefore based on the number of responses received. All 53 respondents who answered the question had a general nursing qualification: 46 (86.79\%) of the 53 respondents had midwifery, 39 (73.58\%) community health nursing, 27 (50.94\%) psychiatric nursing, 27 (50.94\%) primary health care (PHC), and 17 (32.08\%) other qualifications such as nursing education and nursing management.

In order for nurses to work in the community, they are expected to have at least the following qualifications: general nursing, midwifery, community health nursing, and PHC.

The question on number of years of experience was answered by only 48 of the 59 respondents; 16 (33.33\%) of those who answered $(n=48)$ had experience ranging from 10 to 19 years, followed by 15 (31.25\%) with 20-29 years' experience. The range of experience of all respondents who answered the question was between 2 and 45 years (Table 1). According to Cioffi (2001:591), past experiences are intrinsic in decision making and have implications for both clinical and nursing education. Therefore nurses with more years of experience

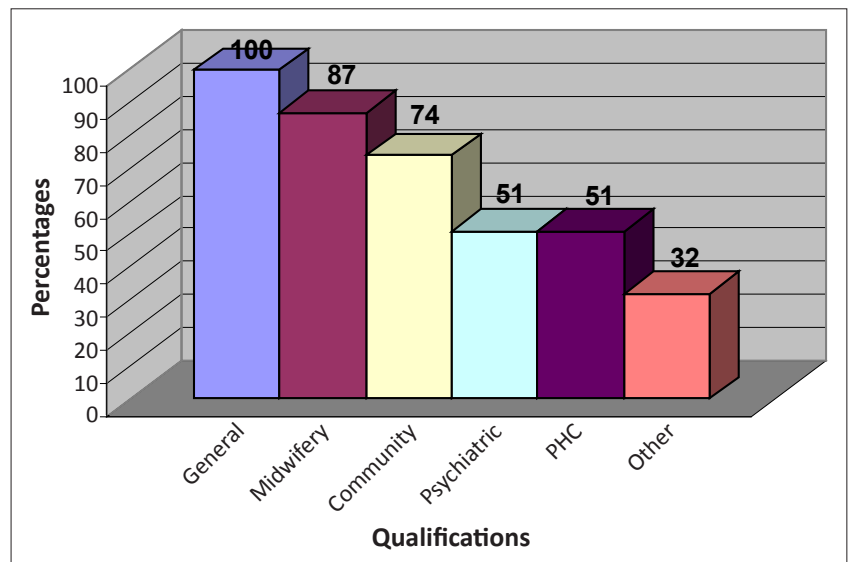

PHC, primary health care.

FIGURE 1: Representation of respondents' professional qualifications $(n=53)$.

TABLE 1: Respondents' years of experience $(n=48)$.

\begin{tabular}{lll}
\hline Responses & $\boldsymbol{f}$ & $\%$ \\
\hline $00-09$ & 12 & 25.00 \\
$10-19$ & 16 & 33.33 \\
$20-29$ & 15 & 31.25 \\
$30-39$ & 3 & 6.25 \\
$40-49$ & 2 & 4.17 \\
\hline Total & $\mathbf{4 8}$ & $\mathbf{1 0 0 . 0 0}$ \\
\hline
\end{tabular}

$n$, Given as number of respondents; $f$, Frequency.

TABLE 2: Respondents' views on whether community nurses should be able to identify tuberculosis symptoms and isolate infectious patients $(n=59)$.

\begin{tabular}{lll}
\hline Responses & $f$ & $\%$ \\
\hline Strongly disagree & 1 & 1.69 \\
Disagree & 0 & 0 \\
Agree & 43 & 72.88 \\
Strongly agree & 15 & 25.42 \\
\hline Total & $\mathbf{5 9}$ & $\mathbf{1 0 0 . 0 0}$
\end{tabular}

$n$, Given as number of respondents; $f$, Frequency. have high levels of emotional competency (Humpel \& Caputi 2001:399). Hill (2010:1) also states that an experienced nurse may assess the same patient as an inexperienced nurse, but respond differently when the condition of the patient changes. The ageing and retirement of numbers of experienced nurses will have a negative impact on patient care, and it is therefore important to develop and implement strategies to retain experienced nurses within the workforce since they are in a position to give the highest quality of care (Hill 2010:7).

\section{Opinions, views and ideas on the role of community nurses in prevention of tuberculosis}

Community nurses should be able to identify tuberculosis symptoms and isolate infectious patients

Only $1(1.69 \%)$ respondent strongly disagreed and none disagreed with the above statement (Table 2). A majority of $43(72.88 \%)$ respondents agreed and $15(25.42 \%)$ strongly agreed with the statement. From these responses it could be concluded that community nurses should be able to identify the symptoms of pulmonary $\mathrm{TB}$ and isolate infectious patients. Nurses have a vital role to play in TB control in terms of identification, infection control and support of newly diagnosed patients (Williams 2006:52). Nurses are often the first to pick up subtle clues and risk factors that could indicate TB infection (Spader 2006:6). In this era of HIV and AIDS and TB, nursing competence in detection, control and care is crucial (Ghebrehiwet 2006:239).

\section{Health education for school children on tuberculosis prevention}

Three $(5.08 \%)$ respondents strongly disagreed and 1 (1.69\%) disagreed with the statement about the importance of health education to school children in order to prevent TB (Figure 2). Most respondents (45-76.27\%) agreed and 10 (16.95\%) strongly agreed with this statement, which indicated that community nurses are fulfilling this role. According to Vlok (2006:524) health education, particularly on TB prevention, should begin early in a person's life. Vlok (2006:524) suggested that community health nurses should go to schools and show films about TB to the principals, teachers and students so that they could learn more about the disease.

\section{Community nurses are no longer fulfilling their role in prevention of tuberculosis since the introduction of direct observed treatment short}

Of the 57 respondents, 24 (42.11\%) strongly disagreed with the above statement, followed by $23(40.35 \%)$ who disagreed, whilst $4(7.02 \%)$ agreed with the statement and $6(10.53 \%)$ strongly agreed (Figure 3). From these responses it could be concluded that a large majority of the respondents $(82.46 \%)$ believed that community nurses have continued fulfilling this role after introduction of DOTS. Community nurses reported that DOTS was an effective strategy to combat nonadherence to treatment regimens (Goodburn \& Drennan 2000:36). Burger (2011:3) stated that 3000 health workers were 
trained by the Department of Health in the management of TB during the 2010 financial year. The department also expanded DOTS by training 2500 community health workers as DOTS supporters who will assist in decreasing the rate of TB defaulters.

\section{Use of community members, such as traditional leaders, can contribute to prevention of multidrug-resistant- tuberculosis}

This question was answered by 57 of the 59 respondents, with $32 \%$ strongly disagreeing or disagreeing with the statement that community members could contribute to prevention of

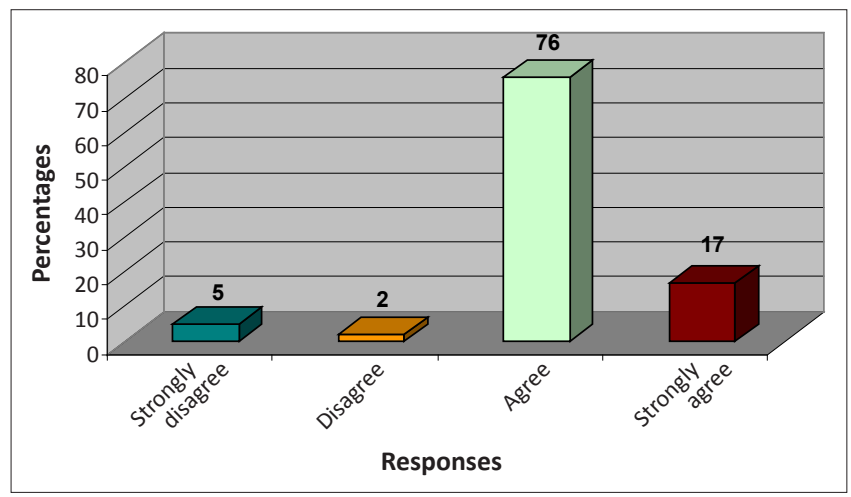

TB, tuberculosis

FIGURE 2: Respondents' views on the importance of providing health education to school children about tuberculosis prevention $(n=59)$.

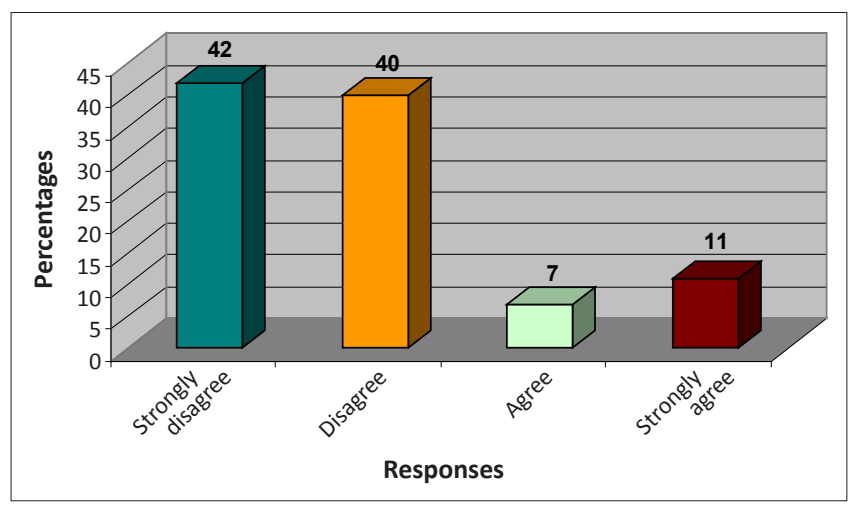

DOTS, direct observed treatment short.

FIGURE 3: Respondents' views on the statement that community nurses have not been fulfilling a role in prevention of tuberculosis since direct observed treatment short $(n=57)$.

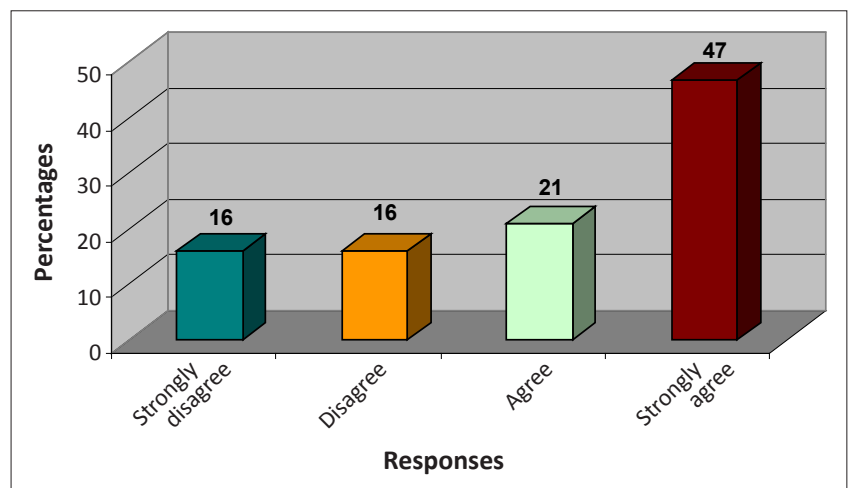

MDR-TB, multidrug-resistant tuberculosis.

FIGURE 4: Respondents' view on whether using traditional leaders can contribute to prevention of multidrug-resistant-tuberculosis $(n=57)$. multidrug-resistant TB (MDR-TB), whilst the majority of $68 \%$ agreed or strongly agreed with the statement (Figure 4).

From these responses it could be concluded that overcoming TB was the responsibility of not only Government but also all citizens (Maher 2003:179). Dick et al. (2007:383) reported that in the Western Cape, PHC nurses established a collaborative partnership between farm workers and their families, their employers and the public health sector to combat TB. Richter and Peu (2004:36) stated that any responsible member of the community can act as a treatment supporter. Because of their respected positions in the community, traditional leaders can be used in the campaign to prevent MDR-TB.

\section{Training of community members}

The question on training of community workers was answered by 57 of the 59 respondents (Table 3). Of those who responded, $5(8.77 \%)$ never trained community members, and $14(24.56 \%)$ seldom trained community members in $\mathrm{TB}$ treatment. Twenty four $(42.11 \%)$ of the respondents trained community members most of the time, whilst 14 (24.56\%) trained them all the time. It was found from the differences in opinions that there are those who train community members and those who do not train them. Ghebrehiwet (2007:4) stated that nurses should train and supervise community members in order to find, educate and treat patients. This is supported by Richter and Peu (2004:35), who indicated that communitybased healthcare workers or informal caregivers need continuous training on family care and poverty alleviation. Peterson, cited in Spader (2006:4), stated that education is the cornerstone of an effective TB prevention and treatment programme. According to Ghebrehiwet (2006:240), nurses in South Africa are working with community volunteers and NGOs to train DOTS supporters in order to prevent development of MDR-TB.

\section{Community nurses' involvement in research}

Of the 55 respondents who answered this question, 9 (16.36\%) indicated that they never engaged in research and 26 $(47.27 \%)$ that they seldom engaged in research (Table 4 ). Fifteen $(27.27 \%)$ indicated that they engaged in research most of the time, and $5(9.09 \%)$ did so all the time. This is a matter of concern, because community nurses work with communities in which there are many challenges that need to be addressed. Research should be conducted into, for example, the views and attitudes of community nurses about research. According to Dreyer, Hattingh \& Lock (1999:35), it is important that community nurses participate in research and that they carry out research at all levels, as research is part of community nursing. Community nurses can contribute towards research about the identification, causes and distribution of diseases (Dreyer et. al 1999:35). Dick et al. (2007:384) described how PHC nurses combined their efforts to design, implement and evaluate an outreach programme to detect and treat $\mathrm{TB}$ patients in order to promote the health of farm workers on 211 farms in the Western Cape of South Africa. 


\section{Problems experienced by community nurses when fulfilling their role in prevention of tuberculosis}

A majority of 33 (55.93\%) respondents experienced problems with defaulters and non-compliance with treatment, followed by $25(42.37 \%)$ who felt that resource shortages were a major problem, $16(27.12 \%)$ who felt that transport problems were a major problem, 15 (25.42\%) who experienced problems with cross-border patients, foreigners, HIV and AIDS and stigmatisation, and 11 (18.64\%) who felt that having no DOTS supporters was a major problem (Table 5). Community nurses have a major role in the detection and treatment of $\mathrm{TB}$, as well as in encouraging patients to adhere to treatment. Hairon (2007:24) stated that if a patient defaulted

TABLE 3: Respondents' views on how often they train community members in tuberculosis treatment $(n=57)$.

\begin{tabular}{lll}
\hline Responses & $f$ & $\%$ \\
\hline Never & 5 & 8.77 \\
Seldom & 14 & 24.56 \\
Most of the time & 24 & 42.11 \\
All the time & 14 & 24.56 \\
\hline Total & $\mathbf{5 7}$ & $\mathbf{1 0 0 . 0 0}$
\end{tabular}

$n$, Given as number of respondents; $f$, Frequency.

TABLE 4: Respondents' views on how often they get involved in research $(n=55)$.

\begin{tabular}{lll}
\hline Responses & $f$ & $\mathbf{\%}$ \\
\hline Never & 9 & 16.36 \\
Seldom & 26 & 47.27 \\
Most of the time & 15 & 27.27 \\
All the time & 5 & 9.09 \\
\hline Total & $\mathbf{5 5}$ & $\mathbf{1 0 0 . 0 0}$
\end{tabular}

$n$, Given as number of respondents; $f$, Frequency.

TABLE 5: Respondents' views on the five biggest problems preventing community nurses from fulfilling their role in the prevention of tuberculosis $(n=59)$.

\begin{tabular}{lll}
\hline Responses & $f$ & $\%$ \\
\hline Transport & 16 & 27.12 \\
No DOTS supporters & 11 & 18.64 \\
Increased defaulters and no compliance & 33 & 55.93 \\
$\begin{array}{l}\text { Shortages of resources, medicines } \\
\text { and nurses }\end{array}$ & 25 & 42.37 \\
$\begin{array}{l}\text { Cross borders, foreigners, HIV and } \\
\text { AIDS and stigma }\end{array}$ & 15 & 25.42 \\
\hline
\end{tabular}

$n$, Given as number of respondents; $f$, Frequency; DOTS, direct observed treatment short.

TABLE 6: Respondents' views on how they handle adherence and abstinence by patients $(n=36)$

\begin{tabular}{lll}
\hline Responses & $f$ & $\%$ \\
\hline Trace - DOTS & 23 & 63.89 \\
Health education - support & 13 & 36.11 \\
\hline Total & $\mathbf{3 6}$ & $\mathbf{1 0 0 . 0 0}$ \\
\hline
\end{tabular}

$n$, Given as number of respondents; $f$, Frequency; DOTS, direct observed treatment short.

TABLE 7: Respondents' views on how often community nurses experience poor communication with patients $(n=55)$.

\begin{tabular}{lll}
\hline Responses & $\boldsymbol{f}$ & $\mathbf{\%}$ \\
\hline Never & 0 & 0 \\
Seldom & 19 & 34.55 \\
Most of the time & 27 & 49.09 \\
All the time & 9 & 16.36 \\
\hline Total & $\mathbf{5 5}$ & $\mathbf{1 0 0 . 0 0}$ \\
\hline
\end{tabular}

$n$, Given as number of respondents; $f$, Frequency. from treatment, nurses should send reminder letters in an appropriate language, do home visits, provide counselling and support for those in poor financial circumstances, and assist or advise patients on how and where to access social services. According to Escott and Walley (2005:1706), DOTS supporters should also provide psychological support and practical help for those without food or funds, as well as tackle the fear and stigma faced by TB patients.

\section{Handling problems of adherence and abstinence in patients}

The question on the issue of adherence and abstinence was answered by only 36 of the 59 respondents (Table 6). Twenty three $(63.89 \%)$ handled problems of adherence and abstinence through DOTS, and $13(36.11 \%)$ provided support and health education to their patients. It was noted that the majority of the respondents ensured that patients take their medication correctly and complete the course through the use of strategies such as DOTS, health education and providing support. Bell (2004:50) stated that nurses should ensure that patients are given the correct medication and provide support to patients and their families or carers in order to prevent treatment lapses. This involves home visits three times a week (Bell 2004:50). According to Goodburn and Drennan (2000:36), it is advisable that a patient should choose his or her own DOTS supporter, as well as for treatment to be decentralised. Dick et al. (2007:385) state that suitable farm dwellers were selected by their peers to be trained as community lay health workers. The WHO (2003), cited in Dick et al. (2007:384), states that in order to adhere to a long course of treatment, peer-group support is needed by the patient.

\section{Poor communication with patients, especially those from} other countries

Of the 55 respondents on this issue, 19 (34.55\%) indicated that they seldom experienced poor communication with patients, $27(49.09 \%)$ that they experienced poor communication with patients most of the time, and $9(16.36 \%)$ that they experienced poor communication all of the time (Table 7). It was found that poor communication with patients is a major problem, as no respondents indicated that they never experienced poor communication. In South Africa alone, people speak a wide variety of languages, such as Siswati, isiXhosa and Sepedi. Communication problems that would already have been prevalent are further aggravated by people coming into South Africa from other countries. Williams (2006:52) stated that it is important that patients understand what is happening and are given the information they need.

\section{Number of community nurses who work with tuberculosispatients in each clinic}

Of the 47 respondents who answered this question, 40 $(85.11 \%)$ had five or fewer nurses working with TB patients in their clinics, and $7(14.89 \%)$ had more than five but not more than 10 (Table 8 ). From these responses it can be deduced that the ratio of nurses to patients could be as high as 1:100 in some clinics. High nurse to patient ratios could lead to poor patient care as a result of overworked and poorly motivated staff members (Lewin et al. 2005:4). The need for community 
health workers is more important than an approach based exclusively on health facilities, hence clear government policy and support for lay health worker programmes is needed in the campaign against TB (Dudley et al. 2003:548).

\section{Staff shortages}

Staff shortages were and still are a problem (Table 9). Most respondents $(22 \%$ - 38.60\%) experienced staff shortages at their clinics all the time, followed by 19 (33.33\%), who experienced this most of the time, 13 (22.81\%), who seldom experienced this, and $3(5.26 \%)$, who had never experienced staff shortages. Torfoss (2007:1) stated that health departments in many countries are faced with human resource shortages, and in order to care for those in need the number of treatment supporters must be increased. In support of this statement, Norvelli (2004:8) stated that shortages of nurses are being felt all over the world. In order to increase the number of nurses available to manage TB, the South African Government is improving working conditions to not only recruit but also retain more nurses (Burger 2007:3). This includes provision of scarce skills and rural allowances (Burger 2007:3). In a broadcast of Ligwalagwala Radio News on 08 October 2008, it was stated that in order to overcome TB the South African Government must first deal with human resource problems. This statement was made by a WHO delegate (identity unknown) on a visit to a TB hospital in KwaZulu-Natal.

\section{Shortages of tuberculosismedication}

The majority of respondents 28 (50.00\%) never experienced shortages of TB medication at their clinics, 25 (44.64\%) seldom experienced shortages, $2(3.57 \%)$ experienced shortages most of the time, and $1(1.79 \%)$ experienced a shortage all of the time (Table 10). It can therefore be concluded that the majority of clinics in the Tshwane Health District of Gauteng Province do not experience TB medication shortages. However, neighbouring countries like Zimbabwe have run short of TB medication, and the request for money to buy TB drugs has not been considered (Lyris ListManager 2006:1). Consequently, people from neighbouring countries such as Zimbabwe cross the border into South Africa in order to obtain treatment, causing a strain on the economy of the area.

\section{Community nurses contract tuberculosiswhilst working with tuberculosispatients}

Most respondents $(42 \%-73.68 \%)$ indicated that they seldom experienced the problem of community nurses contracting $\mathrm{TB}$ whilst working with TB patients, whilst $8(14.04 \%)$ indicated that they experienced this most of the time (Table 11). None indicated that they experienced this all the time. This is good news. However, 8 respondents experiencing it most of the time is high in relation to the total number who answered this question. According to Naidoo and Jinabhai (2006:676), the rate of infection with TB amongst health workers in eThekwini Municipality public sector hospitals was higher than the infection rate in the community, and was increasing yearly. Chanda and Gosnell (2006:1) stated that there had been a rise in the mortality and morbidity of nurses from TB.

\section{Is Government doing enough to protect nurses who work with tuberculosispatients from contracting tuberculosison duty?}

Of the 57 respondents, $55(96.49 \%)$ responded to the above question with a ' $\mathrm{No}^{\prime}$ ', and only 2 (3.51\%) answered 'Yes'. It was interesting to note that most respondents felt that government was not doing enough to protect nurses who work with TB patients from contracting the disease whilst at work. Tzeng (2005:358) stated that nurses, governments and healthcare institutions should work together to devise effective strategies to protect nurses from occupationally acquired TB.

Respondents who believed that government was doing enough to protect nurses from contracting $\mathrm{TB}$ in the workplace were requested to list measures that were in place

TABLE 8: Respondents' indication of the number of community nurses working with tuberculosis patients in their clinics $(n=47)$.

\begin{tabular}{lll}
\hline Responses & $f$ & $\%$ \\
\hline $0-5$ community nurses & 40 & 85.11 \\
$6-10$ community nurses & 7 & 14.89 \\
\hline Total & $\mathbf{4 7}$ & $\mathbf{1 0 0 . 0 0}$ \\
\hline
\end{tabular}

$n$, Given as number of respondents; $f$, Frequency.

TABLE 9: Respondents' views on how often shortages of staff occurred in their clinics $(n=57)$.

\begin{tabular}{lll}
\hline Responses & $\boldsymbol{f}$ & $\mathbf{\%}$ \\
\hline Never & 3 & 5.26 \\
Seldom & 13 & 22.81 \\
Most of the time & 19 & 33.33 \\
All the time & 22 & 38.60 \\
\hline Total & $\mathbf{5 7}$ & $\mathbf{1 0 0 . 0 0}$ \\
\hline
\end{tabular}

$n$, Given as number of respondents; $f$, Frequency.

TABLE 10: Respondents' views on how often shortages of tuberculosis medication occurred in their clinics $(n=56)$.

\begin{tabular}{lll}
\hline Responses & $\boldsymbol{f}$ & $\mathbf{\%}$ \\
\hline Never & 28 & 50.00 \\
Seldom & 25 & 44.64 \\
Most of the time & 2 & 3.57 \\
All the time & 1 & 1.79 \\
\hline Total & $\mathbf{5 6}$ & $\mathbf{1 0 0 . 0 0}$ \\
\hline
\end{tabular}

$n$, Given as number of respondents; $f$, Frequency.

TABLE 11: Respondents' views on how often community nurses contract tuberculosis whilst working with tuberculosis patients $(n=57)$.

\begin{tabular}{lll}
\hline Responses & $f$ & \% \\
\hline Never & 7 & 12.28 \\
Seldom & 42 & 73.68 \\
Most of the time & 8 & 14.04 \\
All the time & 0 & 0 \\
\hline Total & $\mathbf{5 7}$ & $\mathbf{1 0 0 . 0 0}$ \\
\hline
\end{tabular}

$n$, Given as number of respondents; $f$, Frequency.

TABLE 12: Respondents' views on measures that government should put in place to protect community nurses $(n=55)$.

\begin{tabular}{lll}
\hline Responses & $f$ & $\%$ \\
\hline $\begin{array}{l}\text { Protective clothing: masks, } \\
\text { gloves and gowns }\end{array}$ & 24 & 43.64 \\
Environment: air-conditioner, lights & 22 & 40.00 \\
Information: training of nurses & 8 & 14.55 \\
Prophylactic treatment and screening & 24 & 43.64 \\
Incentives & 4 & 7.27 \\
\hline
\end{tabular}

$n$, Given as number of respondents; $f$, Frequency. 
to protect nurses from contracting TB. The two respondents specified that government provided community nurses with masks and gloves to protect them from contracting TB.

In a second follow-up question, those respondents who did not believe that government was doing enough to protect community nurses from contracting $\mathrm{TB}$ whilst on duty were requested to list the specific measures that government should put in place to protect nurses who work with TB patients from contracting the disease whilst on duty (Table 12).

Of the 55 respondents, 24 (43.64\%) indicated they wanted the government to provide them with personal protective clothing, and $24(43.64 \%)$ indicated that they wanted the government to provide community nurses with prophylactic treatment, as well as screening for $\mathrm{TB}$ and other diseases before placement. From the high number of responses indicating these two measures, it can be concluded that it is a matter of urgency that Government should provide personal protective clothing as well as screening to community nurses. Twenty two $(40.00 \%)$ wanted the government to ensure that clinics are environments conducive to the provision of adequate care, as most of the clinics are stuffy and congested. Eight $(14.55 \%)$ indicated a need for information or training on recent diseases, and $4(7.27 \%)$ indicated that they wanted incentives. The researcher observed that incentives are important to some people, as they need to be recognised for work well done in order to motivate them to work even harder. According to the Draft National Infection Prevention and Control Policy for TB, MDR-TB and extremely drugresistant TB (XDR-TB) (Department of Health 2007:13), staff training should be conducted before initial assignment and continuing education provided annually. For infection control and prevention to be effective, community nurses should understand the importance of the relevant policies and their roles in implementing them (Tzeng 2005:362).

\section{Limitations of the study}

This study was limited to community nurses working in the Tshwane Health District of Gauteng, who were registered with the SANC and had experience of one year or more of working with TB patients. The sample size was small, and therefore the results of this study cannot be generalised to registered nurses in hospital settings or even clinics in the rest of South Africa. As this study was limited to registered community nurses in Tshwane, more studies could be conducted to look at the role that nurses, assistant nurses and enrolled nurses play in the prevention of TB, as these nurses are allocated in the clinics as part of the personnel involved in management of TB.

\section{Recommendations}

The following recommendations stem from this study:

- TB management and prevention should form part of the curricula of community nurses at all levels. Nursing schools should include the role of community nurses in the prevention of TB in their curricula.
- Managers should ensure the safety of their staff by providing them with personal protective clothing as well as training on how to care for and manage patients with MDR-TB and XDR-TB.

- Community nurses should be encouraged to participate in research studies conducted by others and even to conduct research themselves.

- Shortages of staff could be relieved if health caregivers and volunteers are recruited to help with home-based health care, including home visits, providing health education and awareness campaigns under supervision of registered community nurses (Richter \& Peu 2004:36).

- The respondents felt that the government was not doing enough to protect them from contracting $\mathrm{TB}$, and suggested the following measures to be taken by government:

- Healthcare providers should be screened before employment, provided with prophylactic treatment when needed and, when TB is contracted on duty, treatment should be provided free of charge.

- Government should provide community nurses as well as the public with training on current health issues, such as TB, MDR-TB and XDR-TB.

- Government and business people should support TB programmes by providing money to NGOs and DOTS supporters in order to make follow-up visits to patients possible, thus reducing the number of defaulters.

- Stringent measures should be taken at all border points to ensure that those entering the country are screened for diseases like TB, MDR-TB and XDR-TB.

\section{Conclusions}

Effective TB control could be achieved if health services could work in partnership with patients, their families and the community at large. Data on the role of community nurses in the prevention of TB in the Tshwane Health District of Gauteng, obtained from respondents who completed a structured questionnaire, are supported by information gained from the literature. The literature control following the data collection and analysis confirmed the role of community nurses in preventing and combatting TB in Tshwane Health District in Gauteng Province. The data analysis and literature control further revealed that community nurses encounter problems when fulfilling their role in this regard, and that action is needed to eliminate these problems. Based on the results of this research, measures to protect community nurses from contracting TB should be a priority.

\section{Acknowledgements}

The authors would like to acknowledge the following who contributed to the success of the study: the University of Pretoria and Gauteng Department of Health for providing us with permission to conduct the study, community nurses for agreeing to serve as participants, the supervisors who contributed to the success of the study, library staff, editor Mrs H. Liebenberg, and statistician Mrs J. Sommers. 


\section{Competing interest}

The authors declare that they have no financial or personal relationship which may have inappropriately influenced them in writing this paper.

\section{Authors' contributions}

All authors contributed in the process of article writing. The student S.D.M. (SG Lourens Nursing College) was well guided by both M.D.P. (University of Pretoria) and S.M.M. (Clinical Arts and Technology Centre) throughout the research study and article writing.

\section{References}

Bell, C., 2004, 'The treatment of patients with TB and the role of the nurse', Infection Control Fact File 100(36), 48-50.

Burger, D., 2011, 'Government Communication and Information System', in South Africa Yearbook 2010/2011, viewed 08 March 2012, from http://www.info.gov. za/about sa/health.htm

Burger, D., 2007, 'Government Communication and Information System', in South Africa Yearbook 2006/07, viewed 27 November 2007, from http://www.info.gov. za/about sa/health.htm

Burns, N. \& Grove, S.K., 2009, The Practice of Nursing Research, Appraisal, Synthesis, And Generation Of Evidence, 6th edn., Saunders, Elsevier.

Burns, N. \& Grove, S.K., 2007, Understanding nursing research, Building An EvidenceBased Practice, 4th edn., Saunders, Elsevier.

Chanda, D. \& Gosnell, D.J., 2006, 'The impact of tuberculosis on Zambia and the Zambian workforce', Online Journal of Issues in Nursing 11(1), 1-16.

Cioffi, J., 2001, 'A study of the use of past experience in clinical decision making in emergency situations', International Journal of Nursing Studies 38(5), 591-599. http://dx.doi.org/10.1016/S0020-7489(00)00096-1

Department of Health (South Africa), 2007, The draft national infection prevention and control policy for TB, MDRTB and XDRTB, viewed 27 February 2007, from http://www.doh.gov.za/docs/policy/tb/part1.pdf.

Dreyer, M, Hattingh, S. \& Lock, M., 1999, Fundamental aspects of community nursing, 2nd edn., Oxford, Cape Town.

Dick, J., Clarke, M., Van Zyl, H. \& Daniels, K., 2007, 'Primary health care nurses implement and evaluate a community outreach approach to health care in the South African agricultural sector', International Nursing Review 54, 383-390. http://dx.doi.org/10.1111/j.1466-7657.2007.00566.x, PMid:17958668

Dudley, L., Azevedo, V., Grant, R., Schoeman, J.H., Dikweni, L. \& Maher, D., 2003, 'Evaluation of community contribution to tuberculosis control in Cape Town, South Africa', International Journal of Tuberculosis and Lung Disease 7(9), 548-555

Escott, S. \& Walley, J., 2005, 'Listening to those on the frontline: Lessons for community-based tuberculosis programmes from a qualitative study in Swaziland', Social Science \& Medicine, 61(2005), 1701-1710. http://dx.doi.org/10.1016/j socscimed.2005.03.040

Ghebrehiwet, T., 2007, 'Tuberculosis fact sheet', in Nursing Matters, viewed 27 November 2007, from http://www.icn.ch/matters-tb.htm

Ghebrehiwet, T., 2006, 'Nurses in the forefront of tuberculosis prevention, care and treatment', International Nursing Review 53(4), 239-240. http://dx.doi. org/10.1111/j.1466-7657.2006.00531.x, PMid:17083406
Goodburn, A. \& Drennan, V., 2000, 'The use of directly observed therapy in TB: A brief pan-London survey', Nursing Standard 14(46), 36-8. http://dx.doi.org/10.1046/ j.1365-2850.2001.00409.x, PMid:11882159

Hairon, N., 2007, 'Managing the increasing incidence of tuberculosis', Nursing Times 103(14), 23-4.

Hill, K., 2010, 'Improving Quality and Patient Safety by Retaining Nursing Expertise', Online Journal of Issues in Nursing 15(3).

Humpel, N. \& Caputi, P., 2001, 'Exploring the relationship between work stress, years of experience and emotional competency using a sample of Australian menta health nurses', Journal of Psychiatric \& Mental Health Nursing 8(5), 399-403.

Lewin, S., Dick, J., Zwarenstein, M. \& Lombard, C.J., 2005, 'Staff training and ambulatory tuberculosis treatment outcomes: A cluster randomized controlled trial in South Africa', Bulletin of the World Health Organization 83(4), 1-14. PMCid:2623473

Ligwalagwala Radio News, 2008, 'Radio news bulletin', 08 October.

Lyris Listmanager, 2006, 'News items', TB-Related News and Journal Items Weekly Update, 08 June.

Maher, D., 2003, 'The role of the community in the control of tuberculosis' Tuberculosis 83, 177-183. http://dx.doi.org/10.1016/S1472-9792(02)00066-5

Molefe, M., 1999, 'South Africa responds to a TB emergency', International Nurses Review 46(6), 178-180. PMid:10674205

Naidoo, S. \& Jinabhai, C.C., 2006, 'TB in health care workers in KwaZulu-Natal, South Africa', International Journal of Tuberculosis and Lung Disease 10(6), 676-682. PMid:16776456

Norvelli, V., 2004, 'TB clinics short of staff', Nursing Times, 100(32), 5-8.

Parahoo, K., 2006., Nursing research: Principles, process and issues, 2 nd edn., Palgrave Macmillan, Hampshire.

Polit, D.F. \& Beck, C.T., 2012, Nursing research: Generating and Assessing Evidence for Nursing Practice, 9th edn., Lippincott, London.

Richter, M.S. \& Peu, M.D., 2004, The educational and supportive needs of informal care givers working at Refentse Clinic, Hammanskraal', Curationis 27(1), 31-40. PMid:15168623

Smeltzer, S.C., Bare, B.G., Hinkle, J.L. \& Cheever, K.H., 2010, Brunner \& Suddarth's Textbook of Medical-Surgical Nursing, 12th edn., Lippincott, Philadelphia.

South African Nursing Council, 2007, 'Geographical distribution', viewed 09 December 2008, from http://www.co.za/stats/stat2007/Distribution\%202007xls.htm

Spader, C., 2006, 'Career management', in Nursing Spectrum-Career Fitness Online, viewed 20 December 2007, from http://community.nursingspectrum/ MagazineArticles/article.cfm?AID

Torfoss, T., 2007, 'Frontline health workers (FLHW) can organise and encourage...', in Tuberkulose, viewed 01 August 2007, from http://www.lhl.no/portal/page?

Toth, A., Fackelmann, J., Pigott, W. \& Tolomeo, O., 2004, 'Tuberculosis prevention and treatment', Public Health 100(9), 27-30.

Tulchinsky, T.H. \& Varavikova, E.A., 2009, The new public health, 2nd edn., Elsevier Academic Press, Amsterdam.

Tzeng, H.M., 2005, 'Promoting a safer environment as related to occupational tuberculosis: A nursing care quality issue in Taiwan', Journal of Nursing Care Quality 20(4), 356-363. http://dx.doi.org/10.1097/00001786-200510000-00012, PMid:16177588

Van Rensburg, H.C.J., 2004, Health and health care in South Africa, Van Schaik, Pretoria.

Vlok, M.E., 2006, Manual of communicable nursing: Communicable diseases, 5th edn., Juta, Cape Town.

Williams, V.G., 2006, 'Tuberculosis: Clinical features, diagnosis and management', Nursing Standards 20(22), 49-53.

World Health Organization (WHO), 2005, 'WHO declares TB an emergency in Africa', viewed 23 March 2007, from http://www.who.int/mediacentre/news/ release/2005/africa-emergency/en/index.html 